\title{
Case Report on Adult Wilms' Tumor and Review of the Literature
}

\section{Álvaro Sánchez González, $M D^{1^{*}}$, Joseba Salguero Segura, MD², Victoria Gómez Dos Santos, PhD',

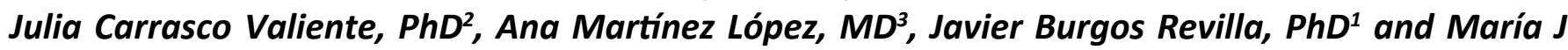 Requena Tapia, PhD'}

${ }^{1}$ Departamento de Urología, IRYCIS, Hospital Universitario Ramón y Cajal, Universidad de Alcalá, Spain

${ }^{2}$ Departamento de Urología, IMIBIC, Hospital Universitario Reina Sofía, Universidad de Córdoba, Spain

${ }^{3}$ Departamento de Anatomía, IMIBIC, Patológica Hospital, Universitario Reina Sofía, Spain

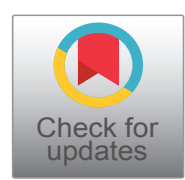

*Corresponding author: Mr. Álvaro Sánchez González, MD, IMIBIC, Hospital Universitario Ramón y Cajal, Universidad de Alcalá, Carretera de Colmenar Viejo Km. 9, 100, 28034 Madrid, Spain, Tel: 0034667976093

\section{Introduction}

Wilms' tumor (WT) or nephroblastoma, is an embryonal kidney cancer, with a low incidence rate in adults, less than 0.2 per million per year [1]. There are no clinical or radiological differences with renal cell carcinoma (RCC), so its diagnosis is unexpected and overdue [2]. In addition, due to its rarity, adequate and risk-adapted treatments, in accordance with international protocols (developed from the pediatric oncology perspective), are delayed [3]. That explains why survival outcomes have been historically worse in adult WC when compared with WT in children [4].

We herein report the case of a 23-years-old patient diagnosed of stage IV rapidly progressive WT, treated with nephrectomy and right lobe partial hepatectomy, who could not start adjuvant chemotherapy because of WT aggressiveness. A review of the previous literature was also performed.

\section{Case Report}

A 23-year-old man was studied in November 2014 for monosymptomatic, left-flank pain, resistant to analgesia.

The abdominal X-ray showed a heterogeneous, calcified, poorly delimited image of $5 \mathrm{~cm}$ in the left hypochondrium (Figure 1). Tumoral markers, and hepatic-renal profiles were normal on blood test. CT scan showed a heterogeneous and calcified left renal mass, sized $12 \times 7.6 \mathrm{~cm}$, dependent on the upper pole, with no vascular invasion. Left hiliar and para-aortic adenopathies, up to $3 \mathrm{~cm}$ were also reported. Moreover, a $4 \times 3.6 \mathrm{~cm}$ hypodense lesion in the $6^{\text {th }}$ hepatic segment, and another one, $12 \mathrm{~mm}$, in the hepatic dome, compatible with metastasis, were described (Figure 1).

On December 2014, elective left radical nephrectomy with loco-regional lymphadenectomy and right lobe partial hepatectomy was performed. Despite a good initial evolution, an urgent open hepaticojejunostomy was performed on the $4^{\text {th }}$ postoperative day, as the patient started with elevation of cholestasis' enzymes, as well as coluria and acolia, and CT scan described intrahepatic bile duct dilatation and pneumoperitoneum. Afterward, the patient evolved favorably, being discharged on January 2015.

Pathology reported a $11 \mathrm{~cm} \mathrm{WT}$, with a three-phase histological pattern (mucinous differentiation and bone metaplasia in the stromal component) (Figure 2). Also described $30 \%$ of necrosis and multiple foci of anaplasia, not reaching the surgical margin. Tumor infiltrated renal capsule and homolateral suprarenal gland respecting surgical-margin.

On immunohistochemical study: Tumor cells expressed diffusely WT1 and maintained nuclear expression with INI1; p53 was over-expressed in anaplasia foci. Tumor infiltration was present in 3 hiliar adenopathies and 2 metastatic foci, not reaching surgical-mar-

Citation: González AS, Segura JS, Santos VGD, Valiente JC, López AM, et al. (2019) Case Report on Adult Wilms' Tumor and Review of the Literature. Int Arch Urol Complic 5:060. doi.org/10.23937/24695742/1510060

Accepted: September 05, 2019: Published: September 07, 2019

Copyright: (c) 2019 González AS, et al. This is an open-access article distributed under the terms of the Creative Commons Attribution License, which permits unrestricted use, distribution, and reproduction in any medium, provided the original author and source are credited. 


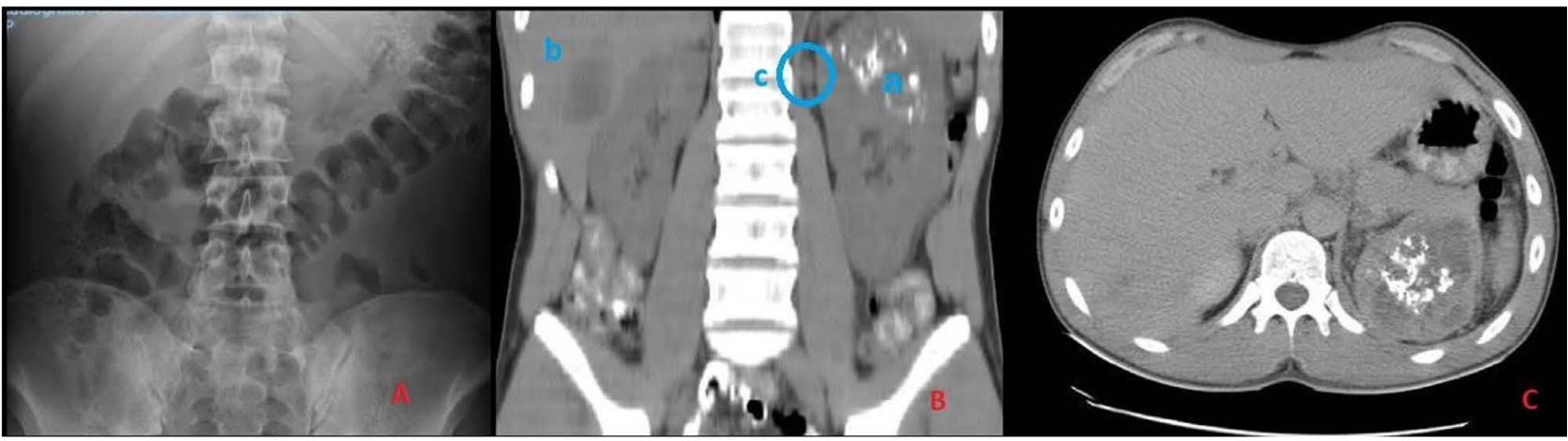

Figure 1: A) Abdominal X-Ray: Heterogeneous, calcified, poorly delimited image of $5 \mathrm{~cm}$ in the left hypochondrium; B) CT scan: Frontal cut in which it is visualized: Calcified and heterogeneous mass of $12 \times 7.6 \mathrm{~cm}$ in left upper renal pole (a); Hypointense image in segment IV's hepatic parenchyma corresponding with metastasis (b); Adenopathy in left renal hilium (c); C) CT scan: Axial cut: Calcified and heterogeneous mass of $12 \times 7.6 \mathrm{~cm}$ in left upper renal pole.

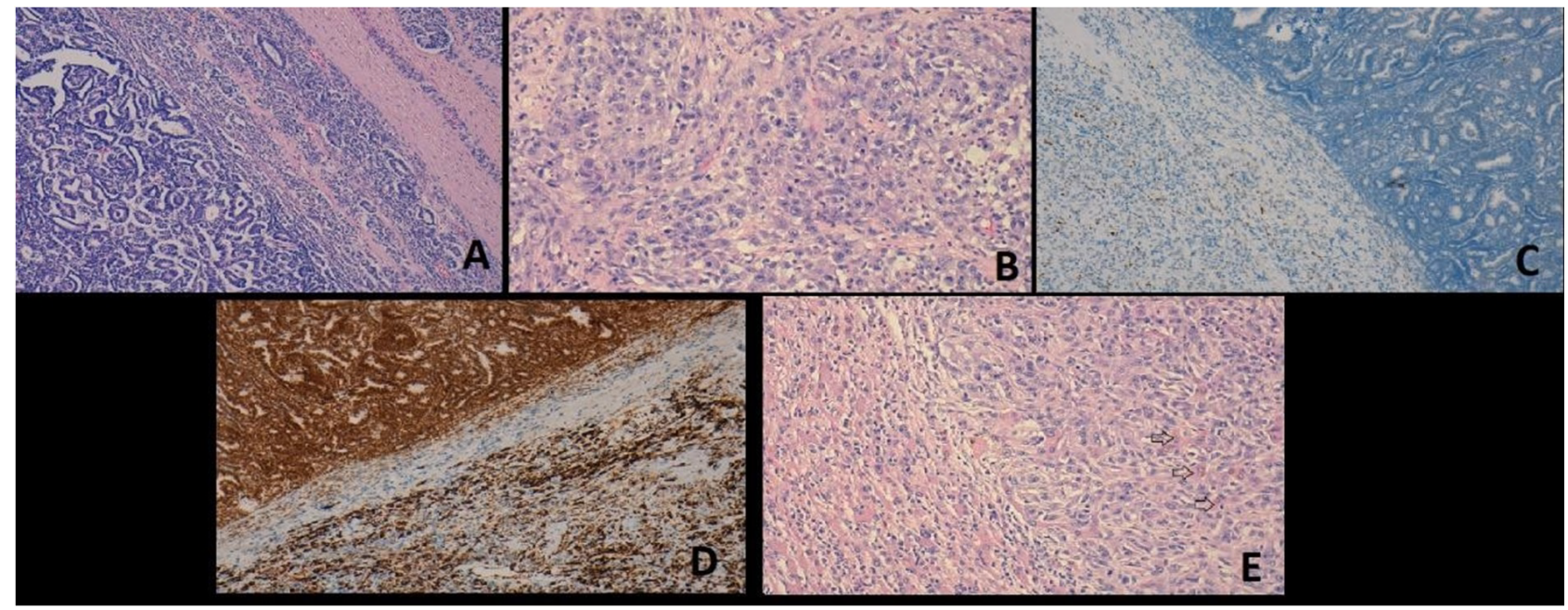

Figure 2: A) Renal Wilms tumor with a classic hematoxiline - eosine histology (left) and less differentiated diffuse pattern (right) $(\mathrm{HE} \times 100)$; B) Anaplastic cells area with big irregular shaped nuclei (HE $\times 200)$; C) Inmunohistochemical stain for p53 was negative in the well differenciated area, while focally positive in anaplastic cells (IHC p53 $\times 100$ ); D) WT1 was diffusely positive in both patterns (IHC WT1 $\times 100)$; E) Wilms tumur metastasis in liver with few trapped hepatocites (arrows) $(\mathrm{HE} \times 200)$.

gin, were found on right hepatectomy.

At the first clinical review, 15 days later, the patient reported dorsal back pain, constitutional syndrome and loss of $14 \mathrm{~kg}$. CT scan showed a large retroperitoneal mass in nephrectomy's bed that extends to the perivascular retroperitoneal space and the ipsilateral psoas muscle. Multiple hypo-attenuating lesions in the liver. Free fluid in right subphrenic space and pelvis of new appearance with peritoneal uptake. Multiple pulmonary nodules in both inferior lobes and lytic lesions in vertebral bodies in relation to metastasis.

Patient was hospitalized, starting symptomatic treatment, and a biopsy of the retroperitoneal mass was performed to confirm the recurrence of nephroblastoma.

The patient suffered a significant deterioration in general condition and dead on February 2015, with no possibility of administering adjuvant chemotherapy treatment.

\section{Discussion}

\section{Epidemiology}

Wilms tumor (WT) is a kidney tumor, extremely rare in adult population, but is the most common solid tumor in children. Adult WT incidence rates vary between 0.17 and 0.27 per million per year. About 70 new adult WT are diagnosed in Europe each year. The proportion of WT among all kidney cancers in adults was $0.33 \%$ or less in most registries [1].

\section{Pathological and radiological diagnosis}

Pathological diagnosis of adult WT is based on 6 criteria: primary renal neoplasm; primitive blastematous spindle or round cell component; formation of abortive or embryonal tubular or glomeruloid structures; no area of tumor diagnostic of hypernephroma; pictorial confirmation of histology ; age over 15-years-old [5].

There is no histopathologic difference between adult or child WT. WT comprises blastemal, stromal 
and epithelial components, which are present in varying proportions. These proportions determine different prognosis. Blastemal predominance is suggested to have poor outcome despite therapy. Epithelial and stromal kinds represent intermediate risk tumors [6-8].

Anaplasia, characterized by multipolar mitotic figures, enlarged nuclei at least three times and hyperchromatic nuclei, is described in approximately $10 \%$ of cases of WT. Its identification, and description of its focal or diffuse distribution is important. Patients with diffuse anaplastic tumors showed a higher relapse rate and worse outcome [6-8].

Immunohistochemistry studies are not normally required, but the presence of cytokeratin, vimentin, desmin, actin, and WT1 allows to distinguish predominant blastemal tumors from rare tumor. WT1 is seen in some blastemal and epithelial elements but not in the stromal components [6-8].

Differential diagnosis between WT and other renal cell cancers is not possible by X-ray, ultrasound or other radiological exam [2]. Contrast-enhanced MRI is the most accurate imaging modality to detect extension local and vascular extension, nephroblastomatosis or contralateral affectation at diagnosis [9]. Nevertheless, abdominal and chest CT scan is recommended by the International Society of Pediatric Oncology (SIOP) to diagnose WT in adults and its local or distant extension [3]. Some studies have been published describing radiological characteristic of WT in both image modalities [10]. Screening of other metastasis sites is not advised unless suggestive symptoms are present. PET-CT currently has no role in the initial diagnosis, but it may be useful at the first relapse to accurate diagnosis of the full metastatic disease [10].

\section{Tumor stage and management}

Staging criteria of WT are based on the anatomic extent of the tumor at nephrectomy piece. There are two main classifications: The National Wilms' Tumor Study Group (NWTS) which proposes a pre-chemotherapy nephrectomy [11]; and the SIOP classification which advises 4-6 cycles of chemotherapy previous to nephrectomy [6] (Table 1).

Table 1: SIOPS and NWSTG Wilms tumor staging system according to anatomical extension.

\begin{tabular}{|c|c|c|}
\hline & $\begin{array}{l}\text { Staging system for renal tumors according SIOP } \\
2001 \text { protocols (after chemotherapy) }\end{array}$ & $\begin{array}{l}\text { Staging system for renal tumors according NWSTG } \\
\text { protocols (before chemotherapy) }\end{array}$ \\
\hline Stage I & $\begin{array}{l}\text { Tumor is limited to the kidney or surrounded with } \\
\text { fibrous pseudocapsule. The renal capsule or } \\
\text { pseudocapsule may be in-filtrated with the tumor, but it } \\
\text { does not reach the outer surface. Tumor is completely } \\
\text { resected. } \\
\text { - Tumor may be protruding into the pelvic system and } \\
\text { "dip- ping" into the ureter but not infiltrates its wall. } \\
\text {-T vessels of the renal sinus are not involved. } \\
\text { - Intrarenal vessel involvement may be present. }\end{array}$ & $\begin{array}{l}\text { Tumor is limited to the kidney and completely resected. } \\
\text { - Tumor was not ruptured before or during removal - } \\
\text { The vessels of the renal sinus are not involved beyond } \\
2 \mathrm{~mm} \text {. } \\
\text {-There is no residual tumor apparent beyond the } \\
\text { margins of excision. }\end{array}$ \\
\hline Stage II & $\begin{array}{l}\text { The tumor extends through the renal capsule into } \\
\text { perirenal fat but is completely resected. } \\
\text { - The tumor infiltrates the renal sinus and/or invades } \\
\text { blood and lymphatic vessels outside the renal } \\
\text { parenchyma but is completely resected. } \\
\text { - The tumor infiltrates adjacent organs or vena cava but } \\
\text { is completely resected. }\end{array}$ & $\begin{array}{l}\text { - Tumor extends beyond the kidney but is completely } \\
\text { excised. } \\
\text { - No residual tumor is apparent at or beyond the } \\
\text { margins of excision } \\
\text { - Tumor thrombus in vessels outside the kidney is stage } \\
\text { II if the thrombus is removed in block with the tumor. }\end{array}$ \\
\hline Stag & $\begin{array}{l}\text { Incomplete excision of the tumor which extends beyond } \\
\text { resection margins - any abdominal lymph nodes are } \\
\text { involved - tumor rupture before or intraoperatively - the } \\
\text { tumor has penetrated through the peritoneal surface - } \\
\text { tumor thrombi present at resection margins of vessels } \\
\text { or ureter. } \\
\text { - The tumor has been surgically biopsied prior to } \\
\text { preoperative chemotherapy or surgery. }\end{array}$ & $\begin{array}{l}\text { Residual tumor confined to the abdomen. } \\
\text { - Lymph nodes in the renal hilum or the periaortic } \\
\text { chains. } \\
\text { - Diffuse peritoneal contamination by the tumor. } \\
\text { - Implants are found on the peritoneal surfaces. } \\
\text { - Tumor extends beyond the surgical margins either } \\
\text { microscopically or glossy. } \\
\text { - Tumor is not completely respectable because of local } \\
\text { infiltration into vital structures. }\end{array}$ \\
\hline Stage IV & $\begin{array}{l}\text { Hematogenous metastases (Lung, liver, bone, brain } \\
\text { etc.) or lymph node metastases outside the abdomino- } \\
\text { pelvic region. }\end{array}$ & $\begin{array}{l}\text { Presence of hematogenous metastases or metastases } \\
\text { to distal lymph nodes. }\end{array}$ \\
\hline Stage V & Bilateral renal tumors at diagnosis. & $\begin{array}{l}\text { Bilateral renal involvement at the time of initial } \\
\text { diagnosis. }\end{array}$ \\
\hline
\end{tabular}




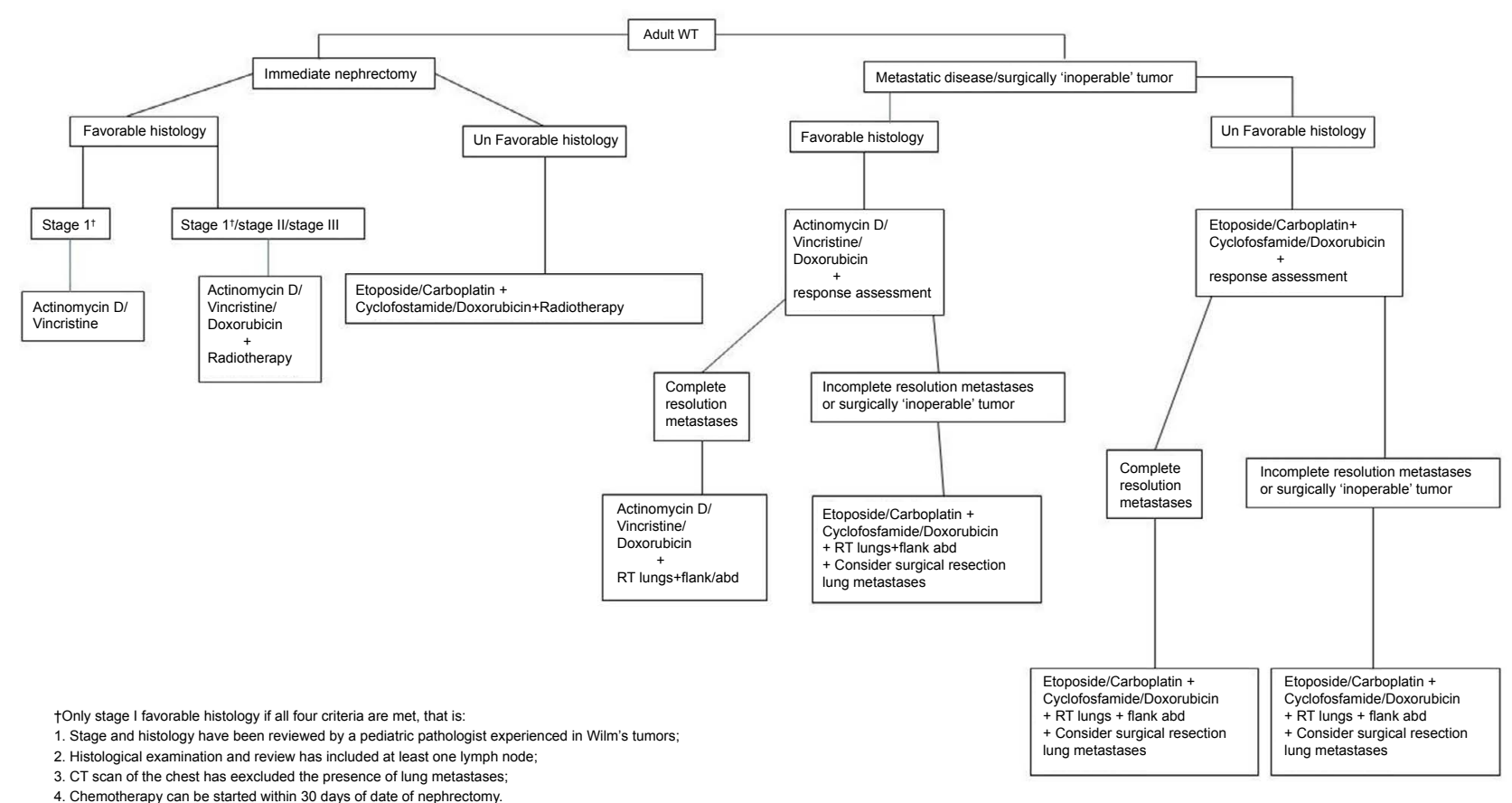

Figure 3: Therapeutic algorithm, proposed by the SIOP and COG, in adults with Wilms tumor according to the performance of previous nephrectomy and the prognostic group [3].

Adult series report a higher incidence of advanced disease (stage III or IV), ranging from 45-70\%, compared with $33 \%$ in pediatric series. Historically, the stage-forstage prognosis in adults was poorer compared with children. Adult WT prognosis has been improved in the last decade by adapting pediatric protocols to adults population, following the recommendations of SIOP and Children's Oncology Group (COG) [3].

This consensus recommends include in pediatrics trials adults who are suitable to be recruited. Moreover, therapeutic recommendations for adult patients who can't be recruited re described in Figure 3 .

In order to anticipate the diagnosis and improve the management of WT by neoadjuvant chemotherapy, some groups propose the performance of renal tumor biopsy (RTB) before nephrectomy [12].

There are several data supporting percutaneous biopsy previously to surgical treatment of renal mass in young adults. On patients aged $18-45$ years, the reported incidence of benign histology on piece is over $20 \%$ [13]. Patients younger than 40 -years-old, just represents $0.5-2 \%$ of all renal cell cancer (RCC) [14]. In addition, the proportion of different histologies of RCC in this group of age, varies with respect to older patient, with a decrease of clear cell RCC [15]. In these patients, nephron sparing management avoid detriment of renal function and the consequent deterioration at cardiovascular level [16]. The median age at presentation of adult WT is 34years, according to EUROCARE study [1].

RTB is a procedure with a high accuracy. The median concordance rate of tumor histology between RTB and surgical pathology vas $90.3 \%$. Median Cohen kappa coefficient value was 0.683 (IQR: 0.52-0.95), indicating a good degree of agreement. It is also a safe procedure with a median overall complication rate of $8.1 \%$, and only a few of the Clavien $>2$ complications $[17,18]$.

It is reported, that not delaying WT diagnosis when it is suspected has a great importance. For this porpoise SIOP and COG recommend refer the nephrectomy sample to a specialized pathologist for WT confirmation, before ruling out other pathologies. Chemotherapy and radiotherapy, if necessary, should be planned to start ideally by day 14 post-nephrectomy, although delaying the start until day 30 is acceptable [3]. Tarenziani, et al. reported differences in 5 -years event free survival when starting treatment within 30 days post-surgery (60 \pm $15 \%)$ compared with those who delayed treatment greater than 30 days $(14.3 \pm 13 \%)(p=0.003)$. Differences in OW were $80 \pm 12 \%$ vs. $28,6 \pm 17 \%$ respectively ( $p$ $=0.005)[4]$.

According to SIOP, neoadjuvant chemotherapy for 4-6 weeks reduce tumor size and intraoperative tumor rupture rates, thus, decreasing difficulty of the surgery and local recurrence rates. Therefore, preoperative core biopsy should be considered in young adults (1840 years) to establish proper pathological diagnosis and give the chance of neoadjuvant chemotherapy benefits [3].

\section{Conclusion}

Wilms tumor is a rare entity in adulthood, with a main presentation in the third decade of life. Its diagnosis is histological, since there are no radiological tests 
that differentiate it from other renal tumors. Avidity in the diagnosis, for which expert pathologist should be consulted at the time of suspicion, and the quickness in the beginning of the adjuvant chemotherapy treatment according to the SIOP international consensus (ideally before 14 dais), will mark the prognosis of this pathology.

Renal Cell Carcinoma is infrequent in population under 40-years-old. In these patients, clear cell RCC's histological variants, as WT, are more frequent. Also, benign histologies are reported up to $20 \%$ of series. RTB, allows presurgical diagnosis with $90 \%$ accuracy, and low rate of complications. RTB enable a nephron sparing approach, which is mandatory to preserve renal function, and also, given the opportunity to administer neoadjuvant treatment in tumors as WT, in which it is indicated.

\section{References}

1. Mitry E, Ciccolallo L, Coleman MP, Gatta G, PritchardJones K, et al. (2006) Incidence of and survival from Wilms' tumour in adults in Europe: Data from the EUROCARE study. Eur J Cancer 42: 2363-2368.

2. Kaur N, Gupta A, Attam A, Shrivastava UK, Wadhwa N (2005) Adult Wilms' tumor: Management considerations. Int Urol Nephrol 37: 17-20.

3. Segers H, Van den Heuvel-Eibrink MM, Pritchard-Jones K, Coppes MJ, Aitchison M, et al. (2011) Management of adults with Wilms' tumor: Recommendations based on international consensus. Expert Rev Anticancer Ther 11: 1105-1113.

4. Terenziani M, Spreafico F, Collini P, Piva L, Perotti D, et al. (2004) Adult Wilms' Tumor : A monoinstitutional experience and a review of the literature. Cancer 101: 289-293.

5. Kilton R, Mattews MJ, Cohen MH (1980) Adult Wilms tumor: A report of prolonged survival and review of th literature. $J$ Urol 124: 1-5.

6. Huszno J, Starzyczny-Słota D, Jaworska M, Nowara E (2013) Adult Wilms' tumor - diagnosis and current therapy.
Cent European J Urol 66: 39-44.

7. Md Zin R, Murch A, Charles A (2011) Pathology, genetics and cytogenetics of Wilms' tumour. Pathology 43: 302-312.

8. Vujani GM, Sandstedt B (2010) The pathology of Wilms' tumour (nephroblastoma): The International Society of Paediatric Oncology approach. J Clin Pathol 63: 102-109.

9. Dumba M, Jawad N, Mchugh K (2015) Neuroblastoma and nephroblastoma: A radiological review. Cancer Imaging 15: 5

10. Wu J, Zhu Q, Zhu W, Chen W (2016) CT and MRI imaging features and long-term follow-up of adult Wilms' tumor. Acta radiol 57: 894-900.

11. D'Angio GJ, Breslow N, Beckwith JB, Evans A, Baum H, et al. (1989) Treatment of Wilms' tumor. Results of the Third National Wilms' Tumor Study. Cancer 64: 349-360.

12. Ratajczyk K, Czekaj A, Rogala J, Kowal P (2018) Adult Wilms tumor with inferior vena cava thrombus and distal deep vein thrombosis - A case report and literature review. World J Surg Oncol 16: 38.

13. Eggener SE, Rubenstein JN, Smith ND, Nadler RB, Kontak $\mathrm{J}$, et al. (2004) Renal tumors in young adults. J Urol 171: 106-110.

14. Akhavan A, Richards M, Shnorhavorian M, Goldin A, Gow $\mathrm{K}$, et al. (2015) Pediatric urology renal cell carcinoma in children, adolescents and young adults : A national cancer database study. J Urol 193: 1336-1341.

15. Cohen J, TimsitL MO, Zerbib OD, Rouprêt M, Verkarre V, et al. (2018) Sporadic kidney cancer of young subjects: Study of the clinical and pathological features of a bicentric cohort. Prog Urol 28: 94-106.

16. Daugherty M, Bratslavsky G (2015) Renal cell carcinoma in young patients: A review of recent literature. Curr Urol Rep 16: 1.

17. Marconi L, Dabestani S, Lam TB, Hofmann F, Stewart $F$, et al. (2016) Systematic review and meta-analysis of diagnostic accuracy of percutaneous renal tumour biopsy. Eur Urol 69: 660-673.

18. Haifler M, Kutikov A (2017) Update on renal mass biopsy. Curr Urol Rep 18: 28. 